\title{
The nutritive value of stackburned yellow maize for livestock: tests in vitro and in broiler chicks
}

\author{
BY S. PANIGRAHI ${ }^{1}$, L. A. BESTWICK ${ }^{2}$, R. H. DAVIS ${ }^{2}$ AND C. D. WOOD \\ ${ }^{1}$ Natural Resources Institute, Central Avenue, Chatham Maritime ME4 4TB \\ ${ }^{2}$ Wye College, University of London, Wye, Ashford TN25 5 AH
}

(Received 1 September 1995 - Revised 27 October 1995-Accepted 10 November 1995)

\begin{abstract}
Differences in the nutritive value of four grades of stackburned yellow maize, obtained from a single storage unit in Mozambique, were examined. Samples were analysed for chemical composition, and subjected to the following in vitro assays for estimating digestibility: total dietary fibre and pancreatin for non-ruminants, and gas production using sheep rumen fluid for ruminant livestock. Samples were also fed to broiler chicks at $600 \mathrm{~g} / \mathrm{kg}$ diet in a growth trial. There were no significant differences in crude protein contents of the maize samples, but there was evidence for the development of Maillard reaction products. Detectable amino acids were lower in discoloured maize, with decreases of $52 \%$ in lysine, $35 \%$ in arginine, and $15 \%$ in glycine concentration in the most severely discoloured sample compared with control. Total starch, reducing sugar, acid-detergent fibre and amylase-neutral-detergent fibre values increased, while total non-reducing sugar content decreased with increased discolouration. Total dietary fibre and pancreatin assays indicated a lowering in digestibility of maize with increasing discolouration. Weight gain of chicks $(P=0.0228)$, efficiency of feed utilization $(P=0.0009)$ and the metabolizable energy value of diets decreased $(P<0.0001)$ with increasing stackburn discolouration. There were no significant effects on $\mathbf{N}$ retention of diets. In witro fermentation using sheep rumen fluid showed a linear decrease in gas production with increasing maize discolouration, indicating a reduction in rumen degradability with stackburn.
\end{abstract}

Nutrition value: Maize: Livestock feed

'Stackburn' refers to a brown discolouration that takes place either during post-harvest drying or subsequent storage of cereals under tropical climatic conditions. It is a common problem in developing countries which, by reducing the acceptability of the cereal for human consumption, results in its down-grading. The causes of stackburn and its effects on nutritive value have been studied for rice (Panigrahi et al. 1992). However, for maize the problem has only been highlighted recently in relation to the 1992-3 food-aid operation in southern Africa (Tyler, 1992; Tyler et al. 1994). In Zimbabwe, severely discoloured maize has proven to be unmarketable at times and consequently has been burned or buried. Increasingly, food-aid donors stockpiling large quantities of imported maize (often yellow maize from US sources) have experienced deterioration of stock and recipient rejection, which has been identified as an adverse reaction to discolouration caused by stackburning.

In identifying the problem of maize stackburn and making recommendations for the disposal of affected grain it is essential to understand the nutritional implications of utilizing stackburned maize for human food and animal feed. The Natural Resources Institute has investigated the phenomenon of maize stackburn under field as well as experimental conditions examining, in particular, the association of grain discolouration with physical conditions (temperature and humidity of stack, moisture content of grain) and biological factors (fungal and insect activity). On the basis of these studies it is believed 
that stackburning may be caused by an increase in the temperature of the cereal stacks resulting from the heat of metabolism of fungi. The discolouration itself may be due to condensation of amino acids and reducing sugars which result in the production of coloured polymers via the intermediate colourless Amadori compounds. Such effects are expected to alter significantly the nutritive value of maize.

The purpose of the present study was to quantify the extent and nature of changes in the nutritive value of maize during stackburn by conducting appropriate chemical and biochemical analyses and feeding trials. Since poultry production is often the most profitable alternative use of cereals next to human consumption, nutritive value assessment focused on this species. However, in vitro tests were also conducted to predict digestibility for humans (total dietary fibre and pancreatin assays), and for ruminant livestock (gas production assay).

\section{MATERIALS AND METHODS}

Sample preparation and analysis

Stackburned yellow maize samples, stored in $50 \mathrm{~kg}$ sacks, were obtained from a single storage unit in Mozambique. The maize originated in the USA and had been supplied through the World Food Programme as emergency food aid to that country. Stackburn had occurred during storage in port warehouses over several months following discharge. These sacks were separated into four different grades of stackburn discolouration (brownish) labelled A (control), B, C and D. Four sacks of samples of each grade (i.e. $200 \mathrm{~kg}$ per grade) were mixed in a horizontal mixer to obtain homogeneity, and then subsampled by passing through a sampler divider to obtain $3 \mathrm{~kg}$ samples. From this final sample, forty randomly selected grains were taken for assessment of degree of discolouration. Assessment was conducted subjectively on a 0-6 scale, with 0 representing normal maize (no brown discolouration) and 6 severe discolouration (Table 1).

The $200 \mathrm{~kg}$ samples were ground through a $4 \mathrm{~mm}$ screen for the broiler chick feeding trial, and the final $3 \mathrm{~kg}$ sub-sample was ground through a $1 \mathrm{~mm}$ screen for chemical and biochemical analyses. Chemical analyses included proximate and amino acid compositions, total starch content, reducing and non-reducing sugar contents, fat content and aflatoxin and fumonisin contamination. The proximate composition of maize samples was determined according to the methods recommended by the Ministry of Agriculture Fisheries and Food (MAFF, 1986). The amino acid composition of $\mathrm{HCl}$-hydrolysed dried and defatted samples was determined using a Biotronik Amino Acid LC5000 Analyser (Eppendorf-Netheler-Hinz Gmbh, Biotronik Division, Maintal, Germany), and gross energy using a Gallenkamp adiabatic $\mathrm{O}_{2}$ bomb calorimeter (Gallenkamp and Co. Ltd, Loughborough, Leics).

Biochemical assays included total dietary fibre (TDF; Prosky et al. 1985), without the final ashing stage or adjusting for residual $\mathrm{N}$; and pancreatin digestibility using a modification of the method of Zhang et al. (1993). The in vitro gas production technique was used to determine the potential rumen fermentation of the samples. Gas production was measured with a pressure transducer, as described by Merry et al. (1991) and Theodorou et al. (1994), and using sheep-rumen fluid in a $\mathrm{N}_{2}$-free medium (Menke et al. 1979). The volume of gas produced was measured every $3 \mathrm{~h}$ initially, then at lengthening intervals as the rate of production declined. Each fermentation was performed in triplicate for $45 \mathrm{~h}$.

For aflatoxin determination, $25 \mathrm{~g}$ samples were extracted with $800 \mathrm{ml} / 1$ acetone in water $(150 \mathrm{ml})$ and filtered using Whatman No. 4 paper. Portions of $5 \mathrm{ml}$ were applied on preconditioned phenyl-bonded phase columns (Bond-Elut, Varian UK Ltd, Walton-onThames, Surrey) in $60 \mathrm{ml}$ water-methanol-acetic acid $(92 \cdot 7: 6 \cdot 7: 1$, by vol.) and $3 \mathrm{ml}$ lead 
Table 1. Proximate composition and changes in carbohydrate fraction of stackburned maize samples (g/kg DM unless otherwise stated)

\begin{tabular}{|c|c|c|c|c|}
\hline $\begin{array}{l}\text { Maize samples... } \\
\text { Colour grading*... }\end{array}$ & $\frac{A}{1 \cdot 15(\operatorname{SE~0\cdot 111)}}$ & $\begin{array}{c}\mathrm{B} \\
2 \cdot 12(\mathrm{SE} 0 \cdot 157)\end{array}$ & $\begin{array}{c}\mathrm{C} \\
4 \cdot 17(\mathrm{SE} 0 \cdot 189)\end{array}$ & $\begin{array}{c}\mathrm{D} \\
5 \cdot 10(\operatorname{SE} 0 \cdot 138)\end{array}$ \\
\hline $\mathrm{DM}(\mathrm{g} / \mathrm{kg})$ & $887 \cdot 6$ & $886 \cdot 8$ & $891 \cdot 6$ & 890.8 \\
\hline Crude protein & $87 \cdot 2$ & 84.6 & 85.9 & 86.8 \\
\hline Crude fat & $37 \cdot 0$ & $35 \cdot 5$ & $35 \cdot 6$ & 33.9 \\
\hline Crude fibre & $17 \cdot 4$ & $18 \cdot 0$ & $21 \cdot 3$ & 21.7 \\
\hline Acid-detergent fibre & $27 \cdot 9$ & $28 \cdot 1$ & $30 \cdot 3$ & $44 \cdot 2$ \\
\hline Amylase-neutral-detergent fibre & $133 \cdot 6$ & $154 \cdot 8$ & $207 \cdot 7$ & $292 \cdot 3$ \\
\hline Gross energy (MJ/kg DM) & 18.62 & 18.52 & 18.63 & 18.49 \\
\hline Ash & $13 \cdot 0$ & 12.6 & $12 \cdot 6$ & $12 \cdot 7$ \\
\hline Calcium & 0.23 & $0 \cdot 30$ & 0.36 & $0 \cdot 41$ \\
\hline Phosphorus & $1 \cdot 1$ & $1 \cdot 3$ & $1 \cdot 3$ & $1 \cdot 5$ \\
\hline Total starch & $719 \cdot 0$ & $717 \cdot 3$ & $733 \cdot 0$ & $737 \cdot 3$ \\
\hline Total reducing sugars & 8.06 & $10 \cdot 46$ & $10-51$ & $11 \cdot 19$ \\
\hline Total non-reducing sugars & 6.25 & $2 \cdot 36$ & 1.05 & 0.49 \\
\hline
\end{tabular}

* Based on examination of forty individual grains per colour grade of sample.

acetate solution $(200 \mathrm{~g} / \mathrm{l})$. The column was washed with water, and aflatoxins eluted with chloroform through an anhydrous $\mathrm{Na}_{2} \mathrm{SO}_{4}$ column before drying in a flow of $\mathrm{N}_{2}$ at $45^{\circ}$. Aflatoxin concentration was determined by high performance thin layer chromatography (HPTLC). For fumonisin determination, $50 \mathrm{~g}$ samples were blended in $200 \mathrm{ml}$ methanolwater $(3: 1, \mathrm{v} / \mathrm{v})$, filtered through a Whatman $2 \mathrm{~V}$ filter, and the filtrate adjusted to $\mathrm{pH} 6 \cdot 2$ using $\mathrm{KOH}$. The filtrate was passed through a strong anion exchange column (SAX), washed with aqueous methanolic solution followed by methanol. Fumonisin was eluted with acetic acid solution $(50 \mathrm{ml} / 1)$, evaporated to dryness and HPLC-grade methanol added. The fumonisin concentration was determined by HPTLC using a fumonisin B1 standard.

\section{Broiler chick feeding trial}

The maize samples were included at $600 \mathrm{~g} / \mathrm{kg}$ in a broiler chick diet formulated to contain $235 \mathrm{~g}$ crude protein $/ \mathrm{kg}$ and $12.65 \mathrm{MJ}$ metabolizable energy $(\mathrm{ME}) / \mathrm{kg}$. The compositions of the basal diets are shown in Table 2. Each of the four diets was fed to thirty-two 1-d-old Ross-1 broiler cockerels, housed in wire cages in groups of eight initially; the numbers being reduced to six per cage after 2 weeks. The environment was maintained in accordance with Ross Poultry recommendations. The diets were fed ad libitum, and feed intake and weight gain were recorded weekly. Water intake was also recorded during the first 2 weeks. A nutrient retention study was conducted between 18 and $21 \mathrm{~d}$, using the total-collection method and freeze-drying the excreta. After $28 \mathrm{~d}$, feed was removed (water provided) for $20 \mathrm{~h}$ before slaughter and a post-mortem examination. The weights of liver and pancreas were recorded. Diets and excreta were analysed for gross energy and $\mathbf{N}$ contents. Dry matter, $\mathrm{N}$ retention, and apparent metabolizable energy (AME) values of diets were determined. The AME values were corrected for $\mathrm{N}$ equilibrium or zero retention (AMEn) using a factor of $34.4 \mathrm{KJ} / \mathrm{g} \mathrm{N}$ retained in the body.

\section{Statistical analyses}

Experimental data were treated by one-way ANOVA using the Statgraphics for PC computer software (Statgraphics Statistical Graphics System, Educational Institution Edition Version 5.0, Statistical Graphics Corporation, USA), with the relationship between 
Table 2. Composition of the basal broiler diet ( $\mathrm{g} / \mathrm{kg}$ unless otherwise stated)

\begin{tabular}{lc}
\hline \hline Ingredients & Inclusion rate \\
Maize & $600 \cdot 0$ \\
Fishmeal & $107 \cdot 6$ \\
Soyabean meal & $232 \cdot 9$ \\
Sunflower meal & $37 \cdot 6$ \\
Maize oil & $8 \cdot 3$ \\
Limestone & $5 \cdot 9$ \\
Salt & $1 \cdot 2$ \\
Methionine & $1 \cdot 1$ \\
Dicalcium phosphate & $0 \cdot 4$ \\
Vitamin and mineral premix $*$ & $5 \cdot 0$ \\
Calculated composition & \\
Moisture & $883 \cdot 0$ \\
Crude protein & $235 \cdot 0$ \\
Crude fibre & $32 \cdot 2$ \\
Crude fat & $45 \cdot 9$ \\
Ash & $65 \cdot 7$ \\
Calcium & $13 \cdot 0$ \\
Phosphorus & $7 \cdot 5$ \\
Lysine & $1 \cdot 40$ \\
Methionine + cystine & $0 \cdot 95$ \\
Metabolizable energy (MJ/kg) & $12 \cdot 65$ \\
\hline
\end{tabular}

* Broiler premix supplied by Vitamealo, Broadmead Lane, Keynsham, Bristol BS18 1ST.

performance variables and discolouration intensity in maize being examined by simple linear regression (mean colour scores were correlated with primary data from individual treatments).

\section{RESULTS}

Chemical composition of maize samples

The aflatoxin and fumonisin contents of maize samples are shown in Table 3. The aflatoxin contents of maize samples were very low, the values being $6 \cdot 1,12 \cdot 2,0 \cdot 6$, and $0.7 \mathrm{ng} / \mathrm{g}$ for samples A, B, C and D respectively. However, whilst fumonisin B1 was detected in samples $\mathrm{A}$ and $\mathrm{C}$ at concentrations of 624 and $626 \mathrm{ng} / \mathrm{g}$ it was non-detectable in the other two samples.

The proximate composition and changes in polysaccharide fraction of the maize samples are presented in Table 1 , and their amino acid composition is shown in Table 4 . Whilst there were no significant differences in the crude protein content of the four samples, there was a lowering of approximately $9 \%$ in detectable amino acids in the most severely discoloured maize sample compared with the control. The major reductions were in the contents of lysine $(>-50 \%)$, arginine $(-37 \%)$, and glycine $(-15 \%)$.

There were also changes in the carbohydrate composition. Starch contents varied as 719 , 717,733 and $737 \mathrm{~g} / \mathrm{kg}$; reducing sugar content increased as $8.06,10.46,10.51$ and $11.19 \mathrm{~g} / \mathrm{kg}$; non-reducing sugar content decreased as $6.25,2.36,1.05$, and $0.49 \mathrm{~g} / \mathrm{kg}$; aciddetergent fibre value increased as $27 \cdot 9,28 \cdot 1,30 \cdot 3$, and $44 \cdot 2 \mathrm{~g} / \mathrm{kg}$; and amylase-neutral detergent fibre value increased as $133 \cdot 6,154 \cdot 8,207 \cdot 7$ and $292 \cdot 3 \mathrm{~g} / \mathrm{kg}$ for samples $\mathrm{A}, \mathrm{B}, \mathrm{C}$ and $\mathrm{D}$ respectively.

There were no effects on fat content or fatty acid composition in the maize samples (Table 5). The only trend detected was in the anisidine values, which were lower in maize samples that had greater stackburn discolouration. 
Table 3. Aflatoxin and fumonisin contents of stackburned maize $(\mathrm{ng} / \mathrm{g})^{*}$

\begin{tabular}{llllll}
\hline Maize sample ... & A & B & C & D \\
\hline Aflatoxin B1 & $4 \cdot 1$ & $10 \cdot 4$ & ND & ND \\
Aflatoxin B2 & ND & ND & ND & ND \\
Aflatoxin G1 & ND & ND & ND & ND \\
Aflatoxin G2 & ND & ND & ND & ND \\
Fumonisin B1 & 624 & ND & 626 & ND \\
\hline
\end{tabular}

ND, not detected.

* Limits of detection: aflatoxin $2 \mathrm{ng} / \mathrm{g}$; fumonisin $250 \mathrm{ng} / \mathrm{g}$.

Table 4. Amino acid composition of stackburned-maize samples

\begin{tabular}{|c|c|c|c|c|}
\hline Maize sample ... & A & B & $\mathrm{C}$ & $\mathbf{D}$ \\
\hline \multicolumn{5}{|l|}{ Amino acids $(\mathrm{g} / 16 \mathrm{~g} \mathrm{~N})$} \\
\hline Aspartic acid & $5 \cdot 78$ & 5.65 & $5 \cdot 64$ & $5 \cdot 10$ \\
\hline Threonine & $3 \cdot 27$ & $3 \cdot 40$ & $3 \cdot 27$ & $2 \cdot 87$ \\
\hline Serine & $4-59$ & $5 \cdot 65$ & $4 \cdot 59$ & $4 \cdot 22$ \\
\hline Glutamic acid & $17 \cdot 55$ & $17 \cdot 39$ & 18.04 & $17 \cdot 18$ \\
\hline Glycine & $3 \cdot 79$ & 3.83 & 3.47 & $3 \cdot 25$ \\
\hline Alanine & 6.90 & 7.05 & $7 \cdot 10$ & 6.66 \\
\hline Valine & $4 \cdot 68$ & $4 \cdot 53$ & $4 \cdot 82$ & $4 \cdot 42$ \\
\hline Isoleucine & $3 \cdot 38$ & $3 \cdot 24$ & 3.28 & $3 \cdot 16$ \\
\hline Leucine & $10-58$ & $10 \cdot 74$ & $11 \cdot 40$ & $10 \cdot 73$ \\
\hline Tyrosine & 4.41 & $4 \cdot 24$ & $4 \cdot 19$ & $4 \cdot 40$ \\
\hline Phenylalanine & 4.95 & $4 \cdot 60$ & $4 \cdot 58$ & $4 \cdot 51$ \\
\hline Histidine & $2 \cdot 61$ & $2 \cdot 77$ & $2 \cdot 54$ & $2 \cdot 21$ \\
\hline Arginine & $5 \cdot 45$ & $3 \cdot 85$ & 3.97 & $3 \cdot 50$ \\
\hline Proline & $7 \cdot 51$ & $7 \cdot 58$ & 7.23 & $6 \cdot 61$ \\
\hline Lysine & 3.29 & $2 \cdot 21$ & $2 \cdot 21$ & $1 \cdot 63$ \\
\hline Cystine & $2 \cdot 47$ & $2 \cdot 28$ & $2 \cdot 61$ & $2 \cdot 53$ \\
\hline Methionine & $2 \cdot 37$ & 1.99 & $2 \cdot 12$ & $2 \cdot 15$ \\
\hline Recovery $(\%)$ & $93 \cdot 58$ & $91 \cdot 00$ & 91.06 & $85 \cdot 13$ \\
\hline
\end{tabular}

Table 5. Composition of the fat from stackburned-maize samples

\begin{tabular}{|c|c|c|c|c|}
\hline Maize samples... & A & B & $\mathrm{C}$ & $\mathrm{D}$ \\
\hline Crude fat $(\mathrm{g} / \mathrm{kg})$ & $37 \cdot 0$ & $35 \cdot 5$ & 35.6 & $33 \cdot 9$ \\
\hline Free fatty acids (g/100 g oil) & $36 \cdot 57$ & $48 \cdot 56$ & $30-93$ & $27 \cdot 80$ \\
\hline Anisidine value (g/100 g oil) & $69 \cdot 98$ & 68.37 & 61.52 & $51 \cdot 12$ \\
\hline Peroxide value (g/100 g oil) & 14.64 & $8 \cdot 14$ & $7 \cdot 01$ & $9 \cdot 21$ \\
\hline \multicolumn{5}{|c|}{ Fatty acid composition of fat ( $\mathrm{g} / 100 \mathrm{~g}$ total fatty acids) } \\
\hline $14: 0$ & 0.01 & 0.07 & $0 \cdot 01$ & 0.01 \\
\hline $16: 0$ & 11.03 & $10 \cdot 99$ & $11 \cdot 04$ & $11 \cdot 21$ \\
\hline $18: 0$ & 0.87 & 0.97 & 0.90 & 0.96 \\
\hline $18: 1$ & $23 \cdot 37$ & $22 \cdot 64$ & 22.05 & 21.81 \\
\hline $18: 2$ & $64 \cdot 42$ & $65 \cdot 13$ & $65 \cdot 78$ & 65.79 \\
\hline $18: 3$ & 0.29 & 0.21 & 0.21 & 0.22 \\
\hline
\end{tabular}


Table 6. Results of in vitro assays to assess the nutritional value of stackburned-maize samples

\begin{tabular}{|c|c|c|c|c|c|c|}
\hline Maize sample ... & A & B & $\mathrm{C}$ & D & $\begin{array}{l}\text { Pooled } \\
\text { SEM }\end{array}$ & $\begin{array}{c}\text { Significance of } \\
\text { grade }(P=\text { or }<)\end{array}$ \\
\hline $\begin{array}{l}\text { Total dietary fibre } \\
(\mathrm{g} / \mathrm{kg})\end{array}$ & $149 \cdot 3^{\mathrm{a}}$ & $164 \cdot 5^{b}$ & $162 \cdot 7^{b}$ & $167 \cdot 6^{\mathrm{h}}$ & 1.74 & 0.0146 \\
\hline $\begin{array}{l}\text { Pancreatin } \\
\text { digestibility (\%) }\end{array}$ & $41 \cdot 80^{2}$ & $39 \cdot 62^{\mathrm{ab}}$ & $38.01^{\mathrm{bc}}$ & $36 \cdot 56^{\mathrm{e}}$ & 0.353 & 0.0019 \\
\hline $\begin{array}{l}\text { In vitro gas } \\
\text { production* }\end{array}$ & $186 \cdot 1^{\mathrm{a}}$ & $145 \cdot 7^{\mathrm{b}}$ & $129 \cdot 3^{b}$ & $80 \cdot 1^{c}$ & $3 \cdot 28$ & 0.0001 \\
\hline
\end{tabular}

a, b,e Mean values within a row not sharing a common superscript letter were significantly different, $P<0.05$.

* Measured as $\mathrm{ml} / 45 \mathrm{~h}$.

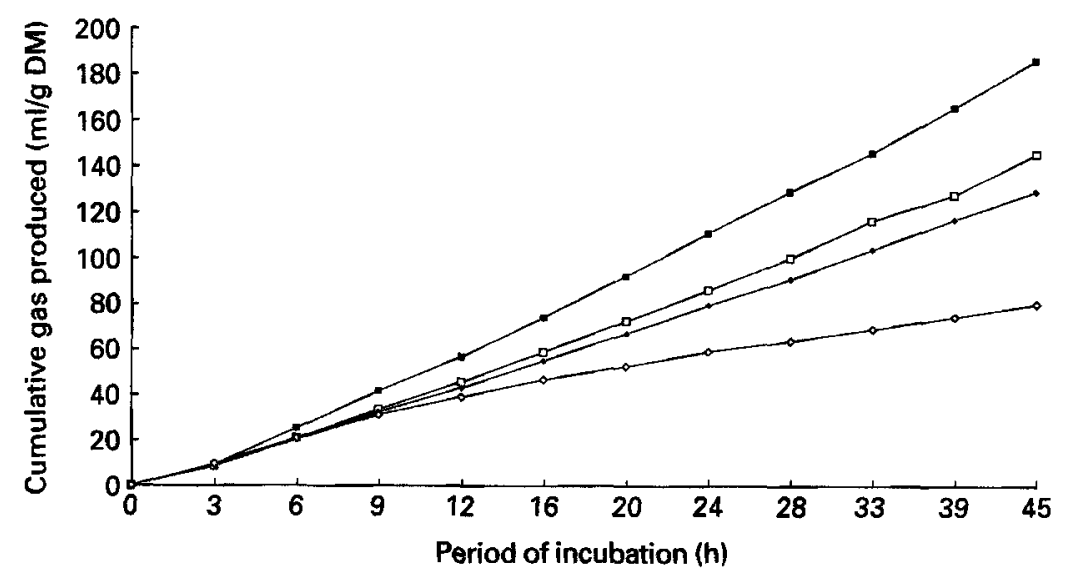

Fig. 1. Volume of gas produced from stackburned-maize samples with different degrees of colouration incubated with sheep rumen fluid in vitro. ( $\square)$, A (control); $(\square), B ;(\diamond), C ;(\diamond), D$. For details of samples and procedures, see p. 98.

\section{Total dietary fibre and pancreatin assay}

These results are summarized in Table 6. Both assays indicated a lowering in the digestibility of stackburned maize with increasing discolouration. The total dietary fibre assay showed a decrease of $12.2 \%$ in digestibility with the most severely discoloured maize compared with controls; the corresponding value in the pancreatin assay being $13.9 \%$.

In vitro gas production assay

The results of the gas production assay are shown in Fig. 1 and Table 6. These show a linear decrease in the fermentation of maize with increasing 'stackburn' discolouration, the reduction being $57 \%$ in the most severely discoloured sample compared with controls. The regression of gas produced at $45 \mathrm{~h} v$. maize colour $(\mathrm{C})$ was given by:

gas produced $=206.9-22.8 \times C ; r^{2}-0.89$,

significance of slope $P<0.0545$, residual standard deviation (RSD) $17 \cdot 49$.

The gas-production figures were more strongly correlated with the amylase-neutral detergent fibre (A-NDF) values than with any other principal component in stackburned 
maize including starch, reducing and non-reducing sugars. The regression of gas produced (45 h) v. A-NDF was given by:

gas produced $=253 \cdot 0-0.60 \times(\mathrm{A}-\mathrm{NDF})$;

$$
r^{2}-0.93 \text {, significance of slope } P<0.0343 \text {, RSD } 10.55 \text {. }
$$

\section{Broiler chick feeding trial}

Growth performance. The results of the feeding trial are summarized in Table 7. The stackburn brown colour was associated with a lowering in weight gain of chicks $(P<$ 0.0228 ), growth rate being $10 \%$ lower with the most severely discoloured maize compared with the control. Efficiency of feed utilization was also lower in stackburned maize samples $(P<0.0008)$. Although overall feed intake was not significantly affected by treatment, there appeared to be some reduction in intakes on diets $C$ and $D$. The results showed intake on diet $\mathrm{B}$ to be slightly higher than that in $\mathrm{A}$, with a lowering taking place in diets $\mathrm{C}$ and $\mathrm{D}$. The regressions of performance variables $v$. maize colour were generally linear as follows:

weight gain $=1220-28 \cdot 1 \times C ; \quad r^{2}-0.51$, significance of slope $P=0.0018$, RSD $46 \cdot 3$;

feed intake $=1738-20.2 \times \mathrm{C}, \quad r^{2}-0.20$, significance of slope $P=0.0782$, RSD 66.9 ;

efficiency of feed utilization $=0.703-0.009 \times \mathrm{C}$;

$$
r^{2}-0.50 \text {, significance of slope } P=0.0022 \text {, RSD } 0.015 \text {. }
$$

Nutrient retention. The nutrient retention data showed a decreasing trend in DM retention and $\mathrm{ME}$ value of diets with increased discolouration of maize. The ash content of excreta decreased with increased discolouration $(P=0.01)$. However, different patterns emerged when retention and energy-balance data were expressed on a DM or an organic matter basis (Figs. 2 and 3). Whilst DM retention and organic matter retention were highly correlated $\left(r^{2} 0.97\right)$, there was no correlation between AME of DM consumed and AME of organic matter consumed $\left(r^{2} 0.07\right)$, the latter decreasing at a lower rate with increasing stackburn than the former. The regressions of nutrient retention variables $v$. maize colour were as follows:

$\mathrm{DM}$ retention $=0.738-0.004 \times \mathrm{C}$;

$r^{2}-0.77$, significance of slope $P<0.0001$, RSD 0.003 ;

organic matter retention $=0.764-0.004 \times C$;

$$
r^{2}-0.77 \text {, significance of slope } P<0.0001, \text { RSD } 0.004 \text {; }
$$

$\mathrm{AME}$ of $\mathrm{DM}=14 \cdot 56-0 \cdot 117 \times \mathrm{C}$;

$r^{2}-0.84$, significance of slope $P<0.0001$, RSD 0.085 ;

$\mathrm{AME}$ of organic matter $=14.45-0.057 \times \mathrm{C}$;

$$
r^{2}-0 \cdot 16 \text {, significance of slope } P=0 \cdot 1267 \text {, RSD } 0 \cdot 222 \text {; }
$$

AMEn of $\mathrm{DM}=13.77-0 \cdot 116 \times \mathrm{C}$;

$$
r^{2}-0.84 \text {, significance of slope } P<0.0001, \text { RSD } 0.085 \text {; }
$$

AMEn of organic matter $=13.61-0.056 \times C$;

$$
r^{2}-0.15 \text {, significance of slope } P=0.1327, \text { RSD } 0.222 \text {; }
$$

$\mathrm{N}$ retention values showed no differences among diets. Water:feed intake ratios were not significantly different for the four treatments.

Post-mortem analysis. Post-mortem analyses revealed no significant effects on the weights of the liver or pancreas. Gross examination of the carcass did not show any evidence of treatment-related tissue damage. 


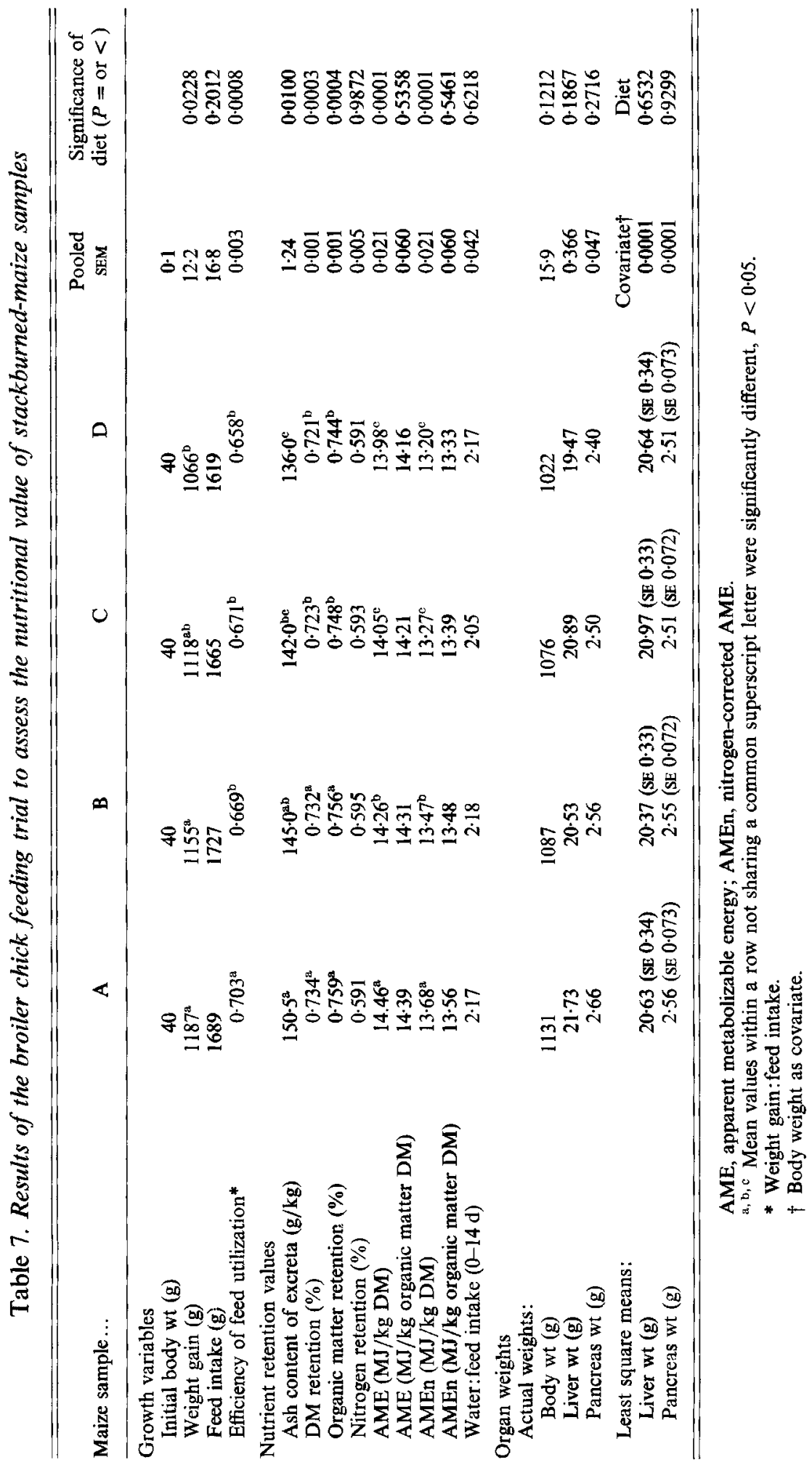




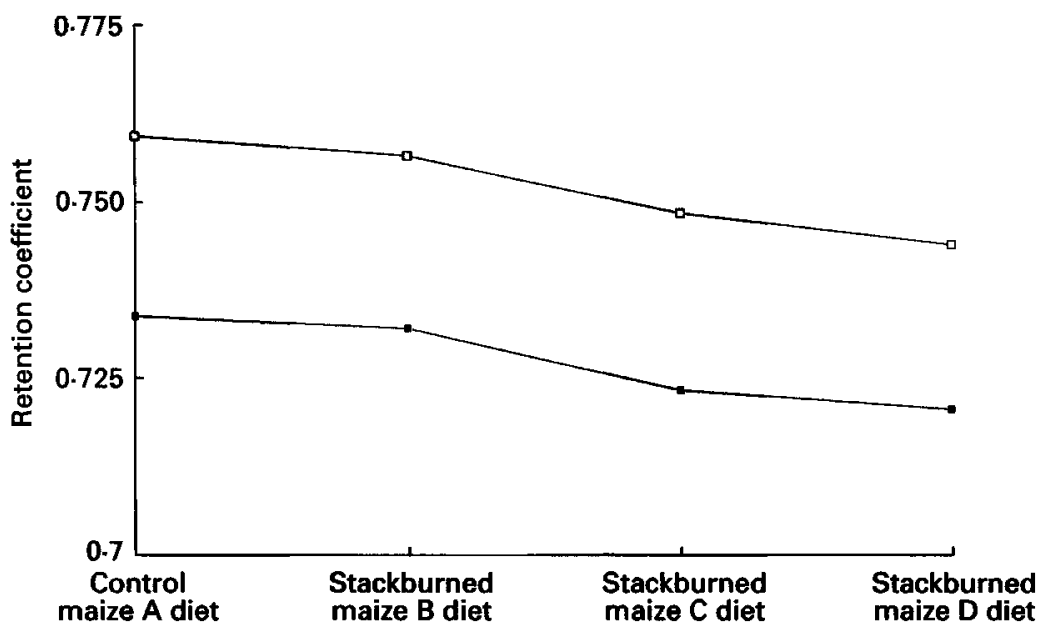

Fig. 2. Dry matter $(\square)$ and organic matter $(\square)$ retention by broiler chicks fed on diets containing stackburnedmaize samples with different degrees of colouration. For details of diets and procedures, see Table 2 and pp. 98-99.

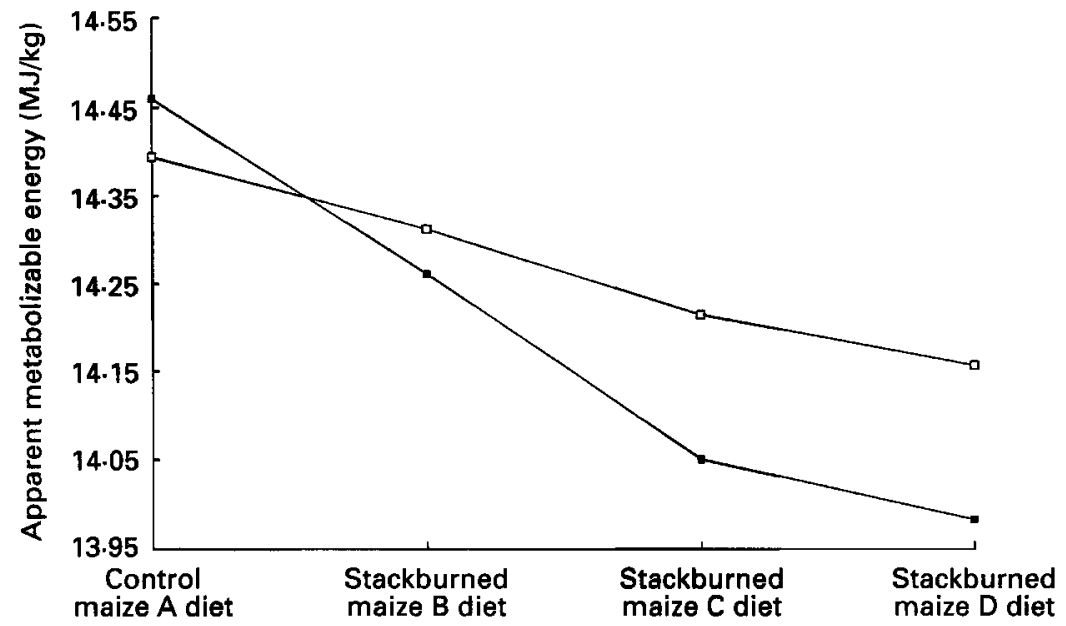

Fig. 3. Apparent metabolizable energy values of diets containing stackburned-maize samples with different degrees of colouration, expressed on a dry-matter basis $(\square)$ and on an organic-matter basis $(\square)$. For details of diets and procedures, see Table 2 and pp. 98-99.

\section{DISCUSSION}

The results of this investigation indicate that the process of stackburn discolouration of maize also produces certain changes in chemical composition that reduce its overall nutritional value. The effects of stackburn on total dietary fibre, pancreatin digestibility, and weight gain of chicks showed an adverse effect in the range of $10-14 \%$ in the most discoloured maize sample compared with control; and a follow-up feeding trial (results not shown) with lower dietary protein and energy concentrations than used in the present experiment also showed a similar degree of effect. These figures may also, therefore, suggest that an excessive depreciation of the financial value of stackburned maize may not be justified, despite its poor appearance that leads to its commercial downgrading. 
The effects of stackburning of maize on nutritive value appear to be primarily due to changes in chemical composition that are consistent with the hypothesis that Maillard reaction products are formed during the process. This is indicated from the dual effects on (a) carbohydrate metabolism, which provided evidence for increased hydrolysis, and (b) reductions in lysine and arginine concentrations. There was, however, no evidence of toxic effects arising from either the products of Maillard reaction between amino acids and sugars, mycotoxin contamination, or the products of oxidation of unsaturated fatty acids. Absence of an effect on the weights of the liver and pancreas might also indicate that antinutritional principles are not formed during maize stackburn. However, the significance of the reduction in anisidine value with increasing stackburn is not clear.

The in vitro assays (total dietary fibre and pancreatin) indicated significant reductions in digestibility of maize for non-ruminant animals with increasing stackburn discolouration. Although neither of the assay results gave strong correlation with weight-gain data from the broiler trial (total dietary fibre $v$. weight gain: $r^{2}-0.36, P=0.0147$; pancreatin $v$. weight gain: $r^{2}+0.51, P=0.0018$ ), the lower digestibility was reflected in the lower growth performance of broiler chicks fed on diets containing the stackburned maize and, more specifically, in a lowering in DM retention and ME value of maize. Whilst the $\mathrm{N}$ retention data did not provide evidence that the digestibility of crude protein was lower in stackburned maize than in the control maize, it is possible that when the diet is limiting in protein, the loss of amino acids through Maillard reaction may become more significant than the reduction in energy value. It is, therefore, probable that reductions in both the ME value and lysine and arginine contents account for most of the deterioration in growth performance observed in the broiler chick trial.

In the broiler experiment a finding of particular interest was the apparent decrease in the ash content of excreta with increasing stackburn discolouration. There is no clear-cut explanation for this, nor for the fact that there were different patterns in the relationship between DM and organic matter retention, which were highly correlated, and between AME of DM and AME of organic matter, which were not correlated. This anomaly might be due to associative effects related to mineral digestion and absorption influencing the AME of diets. Maillard products are documented as inhibiting intestinal transport of some metal ions as well as affecting mineral metabolism (O'Brien \& Morrissey, 1989).

The quantity of gas produced during in vitro fermentation using rumen fluid decreased markedly with increased stackburn, a $57 \%$ reduction being observed for the most severely discoloured sample compared with controls. This strongly suggests that the rumen degradability of maize may decrease with increasing stackburn. This is in accordance with the finding of Marounek \& Brezina (1993) that complexation of glucose and amino acids to form Maillard polymeric compounds lowered the growth rate and growth yields of most rumen bacteria studied. However, the finding does not imply that the same overall effect will take place on productivity in the ruminant animal as increased rumen by-pass of energy and protein may be associated with greater post-rumen digestibility and, therefore, could still result in an overall enhancement of the nutritional value of maize for productive purposes.

Of the growth and nutrient retention variables, weight gain and efficiency of feed utilization were correlated with the colour scores of the four maize samples; the strongest correlation being for the AME. Similarly, gas production in the in vitro assay using rumen fluid was correlated with colour of the maize samples. There is, therefore, scope for standardizing the colour-grading system to enable the nutritive value of stackburned maize for livestock to be predicted.

It is also appropriate to refer to the possibility that fungal contamination of maize might lead to the formation of mycotoxins during storage, an effect that is likely to be 
independent of the process of stackburning. Since aflatoxins and fumonisin are of major significance in terms of depressing poultry growth performance, the samples examined in the present study were screened for these mycotoxins. The aflatoxin contents of maize samples in this study were too low to have affected the broilers, and whilst two of the samples (A and C) contained moderate levels of fumonisin B1, their presence also appears not to have influenced weight gain considering the linear trend with increased stackburn that was observed. However, the results of the mycotoxin assays are presented in Table 2 in view of the considerable uncertainty that exists in the literature on (a) the levels of these mycotoxins that can depress animal performance, either singly or in combination, and (b) the reliability of different methods of detecting the mycotoxins chemically (for example, the analytical method for fumonisin was originally developed for rice and may be subject to interference by the fatty acids present in maize).

Finally, these preliminary results highlight areas where further research is necessary to quantify the net effects of stackburning of maize for different classes of livestock, as well as for its food value for humans. This should include studies of the effects of supplementing the stackburned maize with selected amino acids and energy to determine whether the deterioration in nutritive value can be fully overcome, and a feeding trial with a ruminant species. It is also possible that the samples of maize studied may not have represented the full extent of stackburn discolouration than can occur during storage in the field, so that in more extreme cases, greater detrimental effects on nutritive value might be expected than has been observed from these experiments. Furthermore, in sub-Saharan Africa the predominant maize for human consumption is white, which is also known to develop stackburn during storage. It would be necessary to conduct separate studies on changes in colouration and nutritional value in this type of maize during stackburn.

The authors are grateful to J. Conway for initiating this study and the Cereals and Pulses Food Security Programme of Overseas Development Administration's Natural Resources Division for funding the project. Thanks are also due to Dr D. Hector, Mr A. P. Dutta, Mr B. Roberts and Mr I. Husson for technical assistance during this investigation.

\section{REFERENCES}

Marounek, M. \& Brezina, P. (1993). Heat-induced formation of soluble Maillard reaction products and its influence on utilisation of glucose by rumen bacteria. Archives of Animal Nutrition 43, 45-51.

Menke, K. H., Raab, L., Salewski, A., Stiengass, H., Fritz, D. \& Schneider, W. (1979). The estimation of the digestibility and metabolisable energy content of ruminant feeding stuffs from the gas production when they are incubated with rumen liquor in vitro. Journal of Agricultural Science, Cambridge 93, 217-227.

Merry, R. J., Theodorou, M. K., Raurich, M. G. \& Dhanoa, M. S. (1991). Use of head-space gas pressure in batch cultures to assist in determination of nutritive value of silage to rumen bacteria. In Proceedings of a Conference on Forage Conservation Towards 2000, pp. 451-454 [G. Pahlow, editor]. Institute of Grassland and Forage Research, Federal Research Centre of Agriculture, Braunschweig-Volkenrode, Germany.

Ministry of Agriculture Fisheries and Food (1986). The Analysis of Agriculture Materials. A Manual of the Analytical Methods Used by the Agricultural Development and Advisory Service. Reference Book 427. London: H.M. Stationery Office.

O'Brien, J. O. \& Morrissey, P. A. (1989). Nutritional and toxicological aspects of the Maillard browning reaction in foods. Critical Reviews in Food Science and Nutrition 28, 211-248.

Panigrahi, S., Phillips, S., Plumb, V. E. \& Watson, A. J. (1992). Evaluation of the nutritive value of yellow rice in rats and broiler chicks. British Journal of Nutrition 68, 573-582.

Prosky, L., Asp, N., Furda, I., DeVries, J. W., Schweizer, T. F. \& Harland, B. (1985). Determination of total dietary fibre in foods and food products: collaborative study. Journal of the Association of Official Analytical Chemists 68, 677-679.

Theodorou, M. K., Williams, B. A., Dhanoa, M. S., McAllan, D. B. \& France, J. (1994). A new gas production method using a pressure transducer to determine the fermentation kinetics of ruminant feeds. Animal Feed Science and Technology 48, $185-197$.

Tyler, P. (1992). Heating and discolouration of bagged maize. World Grain September, 14-16. 
Tyler, P. S., Walker, D. J. \& Donaldson, T. J. (1994). Management of Drought-relief Maize: Technical Problems Encountered in Southern Africa During the 1992/93 Food Aid Operation. Chatham: Natural Resources Institute.

Zhang, D., Collins, W. W. \& Belding, S. (1993). Improving sweet potato starch digestibility for animal feeding. Horticultural Science 28, 325-326. 